\title{
HUBUNGAN PENGETAHUAN DAN SIKAP IBU MENYUSUI DENGAN PEMBERIAN ASI EKLUSIF DI PUSKESMAS DARUSALAM
}

\author{
Maida Pardosi \\ Jurusan Kebidanan Politeknik Kesehatan Kemenkes Medan \\ Email ; maidapardosi1963@gmail.com
}

\begin{abstract}
Promotion of Exclusive Breastfeeding has actually been active for a long time, but the reality is that government programs have not run as expected. Therefore, the purpose of this study was to determine the relationship between knowledge and attitudes of breastfeeding mothers with exclusive breastfeeding at the Darussalam Health Center in 2020. This type of research is an analytic survey with a cross sectional approach. The total population is 195 breastfeeding mothers who have babies aged 0-6 months at the Darussalam Health Center and a sample of 66 people. Sampling using accidental sampling technique. Collecting data through interviews using a questionnaire. Data processing with editing, coding, scoring, and tabulating processes. Analytical data analysis, presented in univariate data analysis and bivariate data analysis. For bivariate data, analyze the relationship between variables using chi square. The results showed that from 66 breastfeeding mothers there were 48 breastfeeding mothers (72.7\%) who gave exclusive breastfeeding, 26 breastfeeding mothers (39.4\%) who had sufficient knowledge about exclusive breastfeeding, 53 breastfeeding mothers (80.3\%). who have a positive attitude about exclusive breastfeeding. There is no relationship between knowledge of breastfeeding mothers and exclusive breastfeeding, with the results of the chi-square test, X2 count $<X 2$ table $(1.4<5.591)$ and there is a relationship between the attitudes of breastfeeding mothers and exclusive breastfeeding, with the results of the chi-square test, where X2 count $>$ X2 table $(34.72>3.841)$. The conclusion of this study is that the majority of breastfeeding mothers who give exclusive breastfeeding are 48 people, the majority of breastfeeding mothers have sufficient knowledge, 26 people, and the majority of breastfeeding mothers have a positive attitude 53 people. There is no relationship between knowledge of breastfeeding mothers and exclusive breastfeeding and there is a relationship between attitudes of breastfeeding mothers and exclusive breastfeeding. It is hoped that breastfeeding mothers and the community can improve attitudes in giving exclusive breastfeeding.
\end{abstract}

Keyword : Knowledge, attitude, exclusive breastfeeding

\begin{abstract}
ABSTRAK
Promosi Pemberian Asi Ekslusif sebenarnya secara aktif telah dimulai sejak lama,namun kenyataan program pemerintah belum berjalan sesuai harapan..dan data Puskesmas Darussalam,pada bulan februari 2020 bayi 0-6 bulan yang mendapatkan Asi Ekslusif hanya 11 bayi(5,6) dari 195 bayi,hasil tersebut jauh dari cakupan Puskesmas Darusasalam yaitu $80 \%$.Oleh sebab itu tujuan penelitian ini untuk mengetahui hubungan antara pengetahuan dan sikap ibu menyusui dengan pemberian ASI Eklusif di Puskesmas Darussalam Tahun 2020. Jenis penelitian survey analitik dengan pendekatan cross sectional. Jumlah populasi 195 ibu menyusui yang mempunyai bayi usia 0-6 bulan di Puskesmas Darussalam dan sampel 66 orang. Pengambilan sampel dengan menggunakan teknik accidental sampling. Pengumpulan data melalui wawancara menggunakan kuesioner. Pengolahan data dengan proses editing, coding, scoring, dan tabulating. Analisis data dengan analitik, disajikan dalam analisis data univariat dan analisis data bivariat. Untuk data bivariat menganalisis hubungan antar variabel menggunakan chi square. Hasil penelitian menunjukkan bahwa dari 66 ibu menyusui terdapat 48 ibu menyusui $(72,7 \%)$ yang memberikan ASI eksklusif, 26 ibu menyusui $(39,4 \%)$ yang memiliki pengetahuan cukup tentang pemberian ASI eksklusif, 53 ibu menyusui $(80,3 \%)$ yang memiliki sikap positif tentang pemberian ASI Eksklusif. Tidak ada hubungan Pengetahuan ibu menyusui dengan pemberian ASI eksklusif, dengan hasil uji chi-square, $\mathrm{X}^{2}$ hitung $<2$
\end{abstract}


tabel $(1,4<5,591)$ dan ada hubungan Sikap ibu menyusui dengan pemberian ASI eksklusif, dengan hasil uji chisquare, dimana $\mathrm{X}^{2}$ hitung $>\mathrm{X}^{2}$ tabel $(34,72>3,841)$.

Kesimpulan penelitian ini mayoritas ibu menyusui yang memberikan ASI eksklusif 48 orang, mayoritas ibu menyusui berpengetahuan cukup 26 orang, dan mayoritas ibu menyusui bersikap positif 53 orang. Tidak ada hubungan pengetahuan ibu menyusui dengan pemberian ASI eksklusif dan ada hubungan sikap ibu menyusui dengan pemberian ASI eksklusif. Diharapkan kepada ibu menyusui dan masyarakat agar dapat meningkatkan sikap dalam memberikan ASI eksklusif.

Kata Kunci : pengrtahuan. Sikap, ASI Eksklusif 


\section{PENDAHULUAN}

Millenium Development Goals (MDGs), menargetkan pada tahun 2015 angka kematian ibu menurun sebesar tiga perempat, angka kematian bayi dan angka kematian balita menurun sebesar dua pertiga. Berdasarkan hal tersebut diatas Indonesia mempunyai komitmen untuk menurunkan angka kematian ibu dari 450 pada tahun 1990 menjadi 110/100.000 KH pada tahun 2015. Angka kematian balita juga mencakup angka kematian bayi, karena rentangnya antara usia 0-5 tahun. Indonesia mempunyai komitmen untuk menurunkan angka kematian bayi dan balita dari 97 pada tahun 1990 menjadi 32/1.000 KH pada tahun 2015.

Kebijakan yang ditempuh untuk menurunkan angka kematian bayi adalah meningkatkan pemberian ASI di Indonesia dengan menetapkan 80 persen dari ibu dapat memberikan ASI secara eksklusif. Namun realita menunjukkan, sampai saat ini pemberian ASI eksklusif di Indonesia masih sangat memprihatinkan. Keprihatinan ini cukup mendasar, karena masih banyak masyarakat yang memberikan makanan pendamping pada waktu bayi berumur sangat muda. Keberhasilan ASI eksklusif juga didukung dengan melakukan IMD pada setiap bayi baru lahir.

\section{Tujuan Penelitian} berikut :

Adapun tujuan penelitian ini adalah sebagai

1. Untuk mengetahui distribusi pemberian ASI eksklusif dan yang tidak memberikan ASI eksklusif di Puskesmas Darussalam

2. Untuk mengetahui distribusi pengetahuan ibu menyusui tentang pemberian ASI eksklusif di Puskesmas Darussalam Tahun 2020

3. Untuk mengetahui ditribusi sikap ibu meyusui tentang pemberian ASI eksklusif di Puskesmas Darussalam Tahun 2020

4. Menganalisis hubungan pengetahuan ibu menyusui dengan pemberian ASI eksklusif di Puskesmas Darussalam

Menganalisis hubungan sikap ibu menyusui dengan pemberian ASI eksklusif di Puskesmas Darussalam.

Populasi dalam penelitian ini adalah seluruh ibu menyusui yang memiliki bayi usia 0-6 bulan yang membawa bayinya ke Posyandu Puskesmas Darussalam tahun 2020. Jumlah populasi adalah 195 ibu menyusui.

Sampel pada penelitian ini adalah sebagian Ibu menyusui yang memiliki bayi usia 0-6 bulan yang datang ke Posyandu Puskesmas Darussalam tahun 2020. Rumus yang digunakan untuk menghitung sampel dari populasi yang diketahui jumlahnya adalah sebagai berikut : (Notoatmojdo, 2005)

Maka sampel pada penelitian ini adalah sebanyak 66 orang. Teknik pengambilan sampel dilakukan dengan cara accidental sampling, dimana pengambilan sampel ini dilakukan dengan mengambil responden yang kebetulan ada atau datang ke posyandu di Puskesmas Darussalam

\section{METODE PENELITIAN}

Rancangan Penelitian

Rancangan Penelitian adalah survey analitik rangkaian pendekatan cross sentional yaitu ce $8 \& \& \& \&$ mengambarkan hubungan pengetahuan ibu menyusui dengan pemberian Asi Eksklusif di Puskesmas Darussalam

\section{Metode Pengumpulan Data}

Pengumpulan data menggunakan kusioner yang di berikan kepada Ibu Menyusui bayi usia 0-6 bulan yang membawa ke posyandu Puskesmas Darusalam .jumlah populasi $195 \mathrm{ibu}$ menyusui,kemudian sampel dalam populasi (Natoatmojdo,2005) maka sampai sampel 66 orang yang datang ke puskesmas darusalam selama 1 bulan

\section{Jenis Pengumpulan Data}

Jenis data yang digunakan dalam penelitian ini adalah data primer yang diperoleh langsung dengan menggunakan kuesioner (terlampir), dan data sekunder yaitu jumlah ibu menyusui yang diperoleh dari dokumen Puskesmas Darussalam.

\section{Cara Pengumpulan Data}

Pengumpulan data yang dilakukan dengan membagikan lembar kuesioner kepada reponden yang terlebih dahulu menjelaskan tujuan penelitian.

\section{Hasil Dan Pembahasan}

Tabel 4.1

Distribusi Pemberian ASI eksklusif dan yang Tidak Memberikan ASI eksklusif di Puskesmas Darussalam Tahun 2020

\begin{tabular}{lll}
\hline Pemberian ASI eksklusif & $\mathrm{N}$ & $\%$ \\
\hline Ya (ASI saja) & 48 & 72,7 \\
Tidak (tidak memberikan & 18 & 27,3 \\
ASI eksklusif) & & 100 \\
\hline Jumlah & 66 & \\
\hline
\end{tabular}


Berdasarkan dari tabel 4.1 dapat diketahui bahwa mayoritas ibu memberikan ASI eksklusif yaitu sebanyak 48 orang $(72,7 \%)$ dan minoritas ibu tidak memberikan ASI eksklusif yaitu sebanyak 18 orang $(27,3 \%) .1$

\section{Tabel 4.2}

Distribusi Pengetahuan Responden tentang ASI eksklusif di Puskesmas Darussalam Tahun 2020

Berdasarkan dari tabel 4.1 dapat diketahui bahwa mayoritas ibu menyusui memiliki pengetahuan cukup yaitu sebanyak 26 orang $(39,4 \%)$ dan minoritas memiliki pengetahuan kurang yaitu sebanyak 18 orang $(27,27 \%)$.

Tabel 4.3

Distribusi Sikap Responden tentang ASI eksklusif di Puskesmas Darussalam Tahun 2020

\begin{tabular}{lll}
\hline Sikap & N & \% \\
\hline Positif & 53 & 80,3 \\
Negatif & 13 & 19,7 \\
\hline Jumlah & 66 & 100 \\
\hline
\end{tabular}

Berdasarkan dari tabel 4.3 dapat diketahui bahwa mayoritas ibu menyusui memiliki sikap positif yaitu sebanyak 53 orang $(80,3 \%)$ dan minoritas memiliki sikap negatif yaitu sebanyak 13 orang $(19,7 \%)$.

Tabel 4.4

Hubungan Pengetahuan Ibu Menyusui dengan Pemberian ASI eksklusif di Puskesmas Darussalam Tahun 2020

\begin{tabular}{|c|c|c|c|c|c|c|c|c|}
\hline \multirow{3}{*}{$\begin{array}{l}\text { Pengeta- } \\
\text { huan }\end{array}$} & \multicolumn{4}{|c|}{ Pemberian ASI Eksklusif } & \multirow{2}{*}{\multicolumn{2}{|c|}{ Jumlah }} & \multirow{3}{*}{$\begin{array}{l}\mathrm{X}^{2} \\
\text { hitung }\end{array}$} & \multirow{3}{*}{$\begin{array}{l}X^{2} \\
\text { tabel }\end{array}$} \\
\hline & \multicolumn{2}{|c|}{$\mathrm{Ya}$} & \multicolumn{2}{|c|}{ Tidak } & & & & \\
\hline & $\mathrm{N}$ & $\%$ & $\mathrm{~N}$ & $\%$ & $\mathrm{~N}$ & $\%$ & & \\
\hline Baik & 18 & 27,3 & 4 & 6,1 & 22 & 33,4 & & \\
\hline Cukup & 18 & 27,3 & 8 & 12,1 & 26 & 39,4 & 14 & 550 \\
\hline Kurang & 12 & 18,1 & 6 & 9,1 & 18 & 27,2 & 1,4 & 5,59 \\
\hline Jumlah & 48 & 72,7 & 18 & 27,3 & 66 & 100 & & \\
\hline
\end{tabular}

Berdasarkan tabel 4.4 dapat diketahui bahwa terdapat $26 \mathrm{ibu}$ menyusui $(39,4 \%)$ yang memiliki pengetahuan cukup tentang pemberian ASI eksklusif yaitu sebanyak 18 ibu menyusui $(27,3 \%)$ memberikan ASI eksklusif dan 8 ibu menyusui $(12,1 \%)$ yang tidak memberikan ASI Ekskluisif, terdapat $22 \mathrm{ibu}$ menyusui $(33,4 \%)$ yang memiliki pengetahuan baik tentang pemberian ASI eksklusif yaitu sebanyak 18 ibu menyusui $(27,3 \%)$ memberikan ASI eksklusif dan 4 ibu menyusui $(6,1 \%)$ yang tidak memberikan ASI Ekskluisif, terdapat 18 ibu menyusui $(27,2 \%)$ yang memiliki pengetahuan kurang tentang pemberian ASI eksklusif yaitu sebanyak $12 \mathrm{ibu}$ menyusui $(18,1 \%)$ memberikan ASI eksklusif dan 6 ibu menyusui $(9,1 \%)$ yang tidak memberikan ASI Ekskluisif.

Berdasarkan hasil uji chi-square dengan tingkat kemaknaan $\alpha=0,05$ maka didapat nilai df dari hasil $\mathrm{X}^{2}$ tabel adalah 5,591 dan $\mathrm{X}^{2}$ hitung adalah 1,4.

\begin{tabular}{lll}
\hline Pengetahuan & $\mathrm{N}$ & $\%$ \\
\hline Baik & 22 & 33.33 \\
Cukup & 26 & 39,4 \\
Kurang & 18 & 27,27 \\
\hline Jumlah & 66 & 100 \\
\hline Dimana $\mathrm{X}^{2}$ hitung & $<\mathrm{X}^{2}$ tabel $(1,4<5,591)$. Jadi \\
didapat bahwa tidak adanya hubungan yang \\
signifikan antara pengetahuan ibu menyusui dengan \\
Pemberian ASI eksklusif pada ibu menyusui di \\
Puskesmas Darusaalam Tahun 2020.
\end{tabular}

Tabel 4.5

Hubungan Sikap Ibu Menyusui dengan Pemberian ASI eksklusif di Puskesmas Darussalam Tahun 2020

\begin{tabular}{|c|c|c|c|c|c|c|c|c|}
\hline \multirow{3}{*}{ Sikap } & \multicolumn{2}{|c|}{$\begin{array}{l}\text { Pemberian } \\
\text { Eksklusif }\end{array}$} & & ASI & \multirow{2}{*}{\multicolumn{2}{|c|}{ Jumlah }} & \multirow{3}{*}{$\begin{array}{l}X^{2} \\
\text { hit }\end{array}$} & \multirow{3}{*}{$\begin{array}{l}X^{2} \\
\text { tabel }\end{array}$} \\
\hline & \multicolumn{2}{|l|}{$\mathrm{Ya}$} & \multicolumn{2}{|c|}{ Tidak } & & & & \\
\hline & $\mathrm{N}$ & $\%$ & $\mathrm{~N}$ & $\%$ & $\mathrm{~N}$ & $\%$ & & \\
\hline Positif & 48 & 72,7 & 5 & 7,6 & 53 & 80,3 & & \\
\hline Negatif & 0 & 0 & 13 & 19,7 & 13 & 19,7 & 34,72 & 3,841 \\
\hline Jumlah & 48 & 72,7 & 18 & 27,3 & 66 & 100 & & \\
\hline
\end{tabular}

Berdasarkan tabel 4.5 diketahui bahwa terdapat 53 ibu menyusui $(80,3 \%)$ yang memiliki sikap positif tentang pemberian ASI eksklusif yaitu 
sebanyak 48 ibu menyusui $(72,7 \%)$ yang memberikan ASI eksklusif dan 5 ibu menyusui (7,6\%) yang tidak memberikan ASI eksklusif, terdapat $13 \mathrm{ibu}$ menyusui yang bersikap negatif tentang pemberian ASI eksklusif yaitu sebanyak 13 ibu menyusui $(19,7 \%)$ yang tidak memberikan ASI eksklusif.

Berdasarkan hasil uji chi-square dengan tingkat kemaknaan $\alpha=0,05$ maka didapat nilai df dari hasil $\mathrm{X}^{2}$ tabel adalah 3,841 dan $\mathrm{X}^{2}$ hitung adalah 34,72. Dimana $X^{2}$ hitung $>X^{2}$ tabel $(34,72>3,841)$. Jadi didapat bahwa adanya hubungan yang signifikan antara sikap ibu menyusui dengan Pemberian ASI eksklusif pada ibu menyusui di Puskesmas Darusaalam Tahun 2020

\section{Hubungan Pengetahuan Ibu Menyusui dengan Pemberian ASI eksklusif di Puskesmas Darussalam Tahun 2020}

Berdasarkan tabel 4.5 dapat diketahui bahwa terdapat 26 ibu menyusui $(39,4 \%)$ yang memiliki pengetahuan cukup tentang pemberian ASI eksklusif yaitu sebanyak 18 ibu menyusui $(27,3 \%)$ memberikan ASI eksklusif dan 8 ibu menyusui $(12,1 \%)$ yang tidak memberikan ASI Ekskluisif, terdapat $22 \mathrm{ibu}$ menyusui $(33,4 \%)$ yang memiliki pengetahuan baik tentang pemberian ASI eksklusif yaitu sebanyak 18 ibu menyusui $(27,3 \%)$ memberikan ASI eksklusif dan 4 ibu menyusui $(6,1 \%)$ yang tidak memberikan ASI Ekskluisif, terdapat $18 \mathrm{ibu}$ menyusui $(27,2 \%)$ yang memiliki pengetahuan kurang tentang pemberian ASI eksklusif yaitu sebanyak $12 \mathrm{ibu}$ menyusui $(18,1 \%)$ memberikan ASI eksklusif dan 6 ibu menyusui (9,1\%) yang tidak memberikan ASI Ekskluisif.

Berdasarkan hasil uji chi-square dengan tingkat kemaknaan $\alpha=0,05$ maka didapat nilai df dari hasil $\mathrm{X}^{2}$ tabel adalah 5,591 dan $\mathrm{X}^{2}$ hitung adalah 1,4. Dimana $X^{2}$ hitung $<X^{2}$ tabel $(1,4<5,591)$. Jadi didapat bahwa tidak adanya hubungan yang signifikan antara pengetahuan ibu menyusui dengan Pemberian ASI eksklusif pada ibu menyusui di Puskesmas Darusaalam

\section{Pembahasan}

Dari hasil penelitian mengenai "hubungan pengetahuan dan sikap ibu menyusui dengan pemberian ASI Ekskluisif di Puskesmas Darussalam tahun 2020" maka pembahasannya adalah sebagai berikut :

\section{A. Pengetahuan Ibu Menyusui tentang ASI eksklusif}

Berdasarkan hasil penelitian yang penulis lakukan dengan judul hubungan pengetahuan dan sikap ibu menyusui dengan pemberian ASI Ekskluisif di Puskesmas Darussalam tahun 2020, dapat diketahui bahwa bahwa mayoritas responden memiliki pengetahuan cukup yaitu sebanyak 26 orang $(39,4 \%)$ dan minoritas memiliki pengetahuan kurang yaitu sebanyak 18 orang $(27,27 \%)$.

Menurut Wawan (2011), Pengetahuan adalah merupakan hasil "tahu" dan terjadi setelah orang mengadakan pengindraan terhadap suatu obyek tertentu. Penginderaan terhadap obyek yang terjadi melalui panca indra menusia yakni penglihatan, pendengaran, penciuman, rasa dan raba dengan sendiri. Pada waktu pengindraan sampai menghasilkan pengetahuan tersebut sangat dipengaruhi oleh intensitas perhatian seseorang terhadap suatu obyek. Sebagian besar pengetahuan manusia diperoleh melalui mata dan telinga.

\section{B. Sikap Ibu Menyusui tentang ASI eksklusif}

Berdasarkan hasil penelitian yang penulis lakukan dengan judul hubungan pengetahuan dan sikap ibu menyusui dengan pemberian ASI Ekskluisif di Puskesmas Darussalam tahun 2020, dapat diketahui bahwa mayoritas responden memiliki sikap positif yaitu sebanyak 53 orang $(80,3 \%)$ dan minoritas memiliki sikap negatif yaitu sebanyak 13 orang $(19,7 \%)$.

Eagly dan Chainken (1993) mengemukakan bahwa sikap dapat diposisikan sebagai hasil evaluasi terhadap obyek sikap, yang diekspresikan ke dalam proses-proses kognitif, afektif, dan perilaku. Sebagai hasil evaluasi, sikap yang disimpulkan dari berbagai pengamatan terhadap obyek diekskpresikan dalam bentuk respon kognitif, afektif (emosi), maupun prilaku. (Wawan, 2011)

Hubungan Pengetahuan Ibu Menyusui dengan Pemberian ASI Eksklusif di Puskesmas Darussalam Medan Tahun 2020

Pengetahuan atau Kognitif merupakan dominan yang sangat penting dalam membentuk tindakan seseorang. Berdasarkan hasil penelitian diketahui bahwa dari 66 orang ibu menyusui terdapat 26 ibu menyusui $(39,4 \%)$ yang memiliki pengetahuan cukup tentang pemberian ASI eksklusif yaitu sebanyak $18 \mathrm{ibu}$ menyusui $(27,3 \%)$ memberikan ASI eksklusif dan 8 ibu menyusui $(12,1 \%)$ yang tidak memberikan ASI Ekskluisif, terdapat $22 \mathrm{ibu}$ menyusui $(33,4 \%)$ yang memiliki pengetahuan baik tentang pemberian ASI eksklusif 
yaitu sebanyak 18 ibu menyusui $(27,3 \%)$ memberikan ASI eksklusif dan 4 ibu menyusui $(6,1 \%)$ yang tidak memberikan ASI Ekskluisif, terdapat $18 \mathrm{ibu}$ menyusui $(27,2 \%)$ yang memiliki pengetahuan kurang tentang pemberian ASI eksklusif yaitu sebanyak 12 ibu menyusui $(18,1 \%)$ memberikan ASI eksklusif dan 6 ibu menyusui $(9,1 \%)$ yang tidak memberikan ASI Ekskluisif.

Berdasarkan hasil uji chi-square dengan tingkat kemaknaan $\alpha=0,05$ maka didapat nilai df dari hasil $X^{2}$ tabel adalah 5,591 dan $X^{2}$ hitung adalah 1,4. Dimana $X^{2}$ hitung $<X^{2}$ tabel $(1,4<5,591)$. Jadi didapat bahwa tidak adanya hubungan yang signifikan antara pengetahuan ibu menyusui dengan Pemberian ASI eksklusif pada ibu menyusui di Puskesmas Darusaalam Tahun 2020.

Adanya ibu yang memiliki pengetahuan baik namun tidak memberikan ASI ekskluisf sebanyak 4 ibu menyusui $(6,1 \%)$ dikarenakan ibu tersebut bekerja mulai pagi hingga sore sehingga ibu tidak dapat memberikan ASI secara eksklusif kepada bayinya. Hal ini sejalan dengan pendapat Menurut Roesli (2000) yang menyatakan bahwa sering kali ibu yang bekerja mengalami dilema dalam memberikan ASI eksklusif pada bayinya meskipun kelompok ini tahu manfaat dan keunggulan ASI, namun sulit untuk mempraktekkannya.

Adapun ibu yang berpengetahuan kurang namun memberikan ASI eksklusif sebanyak $12 \mathrm{ibu}$ menyusui $(18,1 \%)$ dikaenakan adanya dukungan dari keluarga dan keadaan ekonomi yang rendah sehingga ibu memberikan ASI eksklusif karena tidak mampu untuk membeli susu formula. Hal ini sejalan dengan pendapat Arif (2009) yang menyatakan bahwa dengan mneyusui secara eksklusif, ibu tidak perlu mengeluarkan biaya untuk makanan bayi sampai bayi berumur 4 bulan. Dengan demikian, akan menghemat pengeluaran rumah tangga untuk membeli susu formula dan peralatannya.

Hasil penelitian ini yang menyatakan bahwa tidak adanya hubungan pengetahuan dengan pemberian ASI eksklusif sejalan dengan hasil penelitian yang dilakukan oleh Nana Yulianah (2013) di wilayah kerja Puskesmas Bonto Cani Kabupaten Bone Tahun 2013 yang menunjukkan bahwa terdapat tidak adanya hubungan yang bermakna antara pengetahuan ibu dengan pemberian ASI eksklusif. Namun berbeda dengan hasil penelitian yang dilakukan oleh Subur Widiyanto (2012) di Desa Kramat Kec. Penawangan Kab. Grobogan yang menunjukkan bahwa terdapat adanya hubungan yang bermakna antara pengetahuan ibu dengan pemberian ASI eksklusif.

Menurut asumsi peneliti, pengetahuan responden tidak berhubungan dengan pemberian ASI eksklusif karena pengetahuan responden yang baik tentang ASI eksklusif belum terwujud dalam tindakan pemberian ASI eksklusif dan dengan pengetahuan yang kurang tidak membuat tindakan menjadi kurang baik. Melalui penyesuaian diri, pengetahuan yang masih kurang dapat disesuaikan dengan berpikir logis untuk melakukan tindakan yang baik. Terdapat berbagai faktor yang bisa mempengaruhi pemberian ASI eksklusif.

\section{Hubungan Sikap Ibu Menyusui dengan Pemberian ASI Eksklusif di Puskesmas Darussalam Medan Tahun 2020}

Berdasarkan hasil penelitian diketahui bahwa dari 66 orang ibu menyusui bahwa terdapat $53 \mathrm{ibu}$ menyusui $(80,3 \%)$ yang memiliki sikap positif tentang pemberian ASI eksklusif yaitu sebanyak 48 ibu menyusui $(72,7)$ yang memberikan ASI eksklusif dan 5 ibu menyusui $(7,6 \%)$ yang tidak memberikan ASI eksklusif, terdapat $13 \mathrm{ibu}$ menyusui yang bersikap negatif tentang pemberian ASI eksklusif yaitu sebanyak 13 ibu menyusui $(19,7 \%)$ yang tidak memberikan ASI eksklusif.

Berdasarkan hasil uji chi-square dengan tingkat kemaknaan $\alpha=0,05$ maka didapat nilai df dari hasil $\mathrm{X}^{2}$ tabel adalah 3,841 dan $\mathrm{X}^{2}$ hitung adalah 34,72. Dimana $X^{2}$ hitung $>X^{2}$ tabel $(34,72>3,841)$. Jadi didapat bahwa adanya hubungan yang signifikan antara sikap ibu menyusui dengan Pemberian ASI eksklusif pada ibu menyusui di Puskesmas Darusaalam Tahun 2020.

Hasil penelitian ini yang menyatakan adanya hubungan sikap ibu menyusui dengan pemberian ASI eksklusif sejalan dengan hasil penelitian yang dilakukan oleh Wenas (2011) di wilayah kerja Puskesmas Tompaso kecamatan Tompaso yang menunjukkan bahwa terdapat adanya hubungan yang bermakna antara sikap ibu dengan pemberian ASI eksklusif.

Namun berbeda dengan hasil penelitian Yulianah (2013) yang menyatakan bahwa tidak ada hubungan yang bermakna antara sikap ibu terhadap pemberian ASI eksklusif. Meskipun sikap responden tidak memiliki hubungan yang bermakna, tetapi data menunjukkan bahwa responden yang memiliki sikap yang positif cenderung memberikan ASI eksklusif dibanding responden yang memiliki sikap yang negatif. 
Adanya ibu menyusui yang memiliki sikap negatif dan tidak memberikan ASI eksklusif sebanyak 13 ibu menyusui (19,7\%) dikarenakan oleh kelemahan instrumen yang digunakan oleh peneliti dan pengaruh lingkungan sekitar. Hal ini sejalan dengan pendapat Maulana (2009), Sikap dapat terbentuk dari adanya interaksi sosial yang dialami individu. Interaksi di sini tidak hanya berupa kontak sosial dan hubungan antar pribadi sebagai anggota kelompok sosial, tetapi meliputi juga hubungan dengan lingkungan fisik maupun lingkungan psikologis sekitarnya.

Menurut asumsi peneliti, sikap responden tentang pemberian ASI eksklusif berhubungan dengan pemberian ASI eksklusif karena sikap responden terbentuk dari interaksi lingkungan sekitar, kelompok sosial, dan psikologi dari ibu.

\section{KESIMPULAN DAN SARAN}

\section{Kesimpulan}

Berdasarkan hasil penelitian mengenai Hubungan Pengetahuan dan Sikap Ibu Menyusui dengan Pemberian ASI eksklusif di Puskesmas Darussalam Tahun 2020 dengan jumlah sampel 66 ibu menyusui dapat diambil kesimpulan sebagai berikut :

1. Terdapat 48 ibu menyusui $(72,7 \%)$ yang memberikan ASI eksklusif dan 18 ibu menyusu $(27,3 \%)$ i tidak memberikan ASI eksklusif.

2. Pengetahuan ibu menyusui tentang pemberian ASI eksklusif, mayoritas ibu menyusui berpengetahuan cukup 26 orang $(39,4 \%)$.

3. Sikap ibu menyusui tentang pemberian ASI eksklusif, mayoritas ibu menyusui bersikap positif 53 orang $(80,3 \%)$.

4. Tidak ada hubungan Pengetahuan ibu menyusui dengan pemberian ASI eksklusif. Dengan hasil uji chi-square, dimana $\mathrm{X}^{2}$ hitung $<\mathrm{X}^{2}$ tabel $(1,4<5,591)$. Dengan demikian tidak terdapat kesenjangan antara peneliti dan teori.

5. Ada hubungan Sikap ibu menyusui dengan pemberian ASI eksklusif. Dengan hasil uji chisquare, dimana $\mathrm{X}^{2}$ hitung $>\mathrm{X}^{2}$ tabel $(34,72>$ 3,841). Dengan demikian tidak terdapat kesenjangan antara peneliti dan teori.

\section{Saran}

Adapun saran yang dapat penulis sampaikan pada penelitian ini adalah sebagai barikut :

1. Bagi Peneliti

Disarankan kepada peneliti untuk melakukan penelitian selanjutnya dengan variabel-variabel yang berbeda agar penelitian ini dapat berkembang.

2. Bagi Ibu Menyusui

Diharapkan kepada ibu menyusui agar dapat meningkatkan pemberian ASI eksklusif dan masyarakat agar dapat meningkatkan sikap dalam memberikan ASI eksklusif.

3. Bagi Puskesmas Darussalam

Disarankan kepada Puskesmas Darussalam untuk memberikan penyuluhan melalui program posyandu tentang pemberian ASI eksklusif.

4. Bagi Peneliti Selanjutnya

Disarankan kepada peneliti selanjutnya agar menggunakan teori dan instrumen yang lebih mendalam untuk melakukan penelitian berikutnya.

\section{DAFTAR PUSTAKA}

Arif, N., 2009. ASI dan Tumbuh Kembang Bayi. Jakarta: Buku Kita

Astutik, R.Y., 2020. Payudara dan Laktasi. Jakarta: Salemba Medika

Depkes RI. (2001). Manajemen Laktasi Buku Panduan Bagi Bidan dan Petugas Kesehatan di Puskesmas. Jakarta: Dirjen Bina Kesehatan Masyarakat. Hidayah, N,. 2013. Millenium Development Goals (MDGs).

lhami, M.F. (2015). Hubungan Pengetahuan Ibu Tentang ASI Eksklusif dengan Tindakan Pemberian ASI Eksklusif di Puskesmas Kartasura. Diakses 19 Februari 2016, https://eprints.ums.ac.id/39484/. Maritalia, D. (2012). Asuhan Kebidanan Nifas dan Menyusui. Yogyakarta: Pustaka Pelajar.

Notoatmodjo, S. (2012). Metodologi Penelitian Kesehatan. Jakarta: PT Rineka Cipta.

Robiwata, M.E., Ciptorini, D., \& Handini, K.D. (2012). Hubungan Tingkat pengetahuan Ibu Tentang ASI Eksklusif dengan Pemberian ASI saja di Wilayah Kerja Puskesmas Kokap 1 Kabupaten Kulon Progo Propinsi Yogyakarta. Diakses 6 April 2016, https://journal.respati.ac.id/index.php/medika/ar ticle/81/77.

Suradi, R dan Hegar. (2010). Indonesia Menyusui. Jakarta: I 